\title{
Dopamine-Grafted Hyaluronic Acid Coated Hyperbranched Poly( $\beta$-Amino Esters)/DNA Nano-Complexes for Enhanced Gene Delivery and Biosafety
}

\author{
Man Guo ${ }^{1}$, Yingcai Meng ${ }^{2, *}$, Xiaoqun Qin ${ }^{1, *}$ and Wenhu Zhou ${ }^{2, *}$ \\ 1 Department of Physiology, Xiangya School of Medicine, Central South University, Changsha 410013, China; \\ guoman@csu.edu.cn \\ 2 Xiangya School of Pharmaceutical Sciences, Central South University, Changsha 410013, China \\ * Correspondence: yingcaimeng@csu.edu.cn (Y.M.); qinxiaoqun@csu.edu.cn (X.Q.); \\ zhouwenhuyaoji@csu.edu.cn (W.Z.)
}

check for updates

Citation: Guo, M.; Meng, Y.; Qin, X.; Zhou, W. Dopamine-Grafted Hyaluronic Acid Coated Hyperbranched Poly $(\beta-A m i n o$ Esters)/DNA Nano-Complexes for Enhanced Gene Delivery and Biosafety. Crystals 2021, 11, 347. https://doi.org/10.3390/cryst 11040347

Academic Editor: Abel Moreno

Received: 2 March 2021

Accepted: 24 March 2021

Published: 29 March 2021

Publisher's Note: MDPI stays neutral with regard to jurisdictional claims in published maps and institutional affiliations.

Copyright: (c) 2021 by the authors. Licensee MDPI, Basel, Switzerland. This article is an open access article distributed under the terms and conditions of the Creative Commons Attribution (CC BY) license (https:/ / creativecommons.org/licenses/by/ $4.0 /)$.

\begin{abstract}
Gene therapy has attracted particular attention for the treatment of various genetic diseases, and the development of gene delivery vectors is of utmost importance for in vivo applications of gene drugs. Various cationic polymers with high nucleic acid loading and intracellular transfection efficiency have been reported, however, their biological applications are limited by potential toxicity. Surface modification is a robust solution to detoxify the cationic vectors, but this can inevitably weaken the transfection efficiency. To address this dilemma, we reported the ability of a dopamine (DA)-grafted hyaluronic acid (HA) to modify gene vectors for enhanced gene delivery and biosafety. The nano-vector was formed by using branched poly( $\beta$-amino esters) (PAEs), and surface coating with HA-DA to form a core-shell nano-structure via electrostatic attraction. Upon HA-DA modification, the biosafety of the gene delivery vehicle was improved, as demonstrated by the cell cytotoxicity assay and hemolysis test. Notably, the nano-system displayed a DA-dependent transfection efficiency, in which a higher DA grafting degree resulted in better efficacy. This can be explained by the adhesive nature of DA, facilitating cell membrane interaction, as well as DA receptor mediated active targeting. At the optimal DA grafting ratio, the nano-system achieved a transfection efficiency even better than that of commonly used polyethylenimine (PEI) vectors. Together with its excellent biocompatibility, the vector presented here holds great promise for gene delivery applications.
\end{abstract}

Keywords: gene delivery; poly( $\beta$-amino esters); surface coating; nanoparticles

\section{Introduction}

Gene therapy is a highly attractive choice for the treatment of various genetic diseases. To achieve effective gene therapy, a general-yet robust-delivery strategy is required in order to facilitate disease targeting and intracellular penetration of the nucleic acid drugs, while protecting unwanted degradation by nucleases during in vivo circulation [1] Towards this goal, the development of suitable delivery vehicles has received a great deal of attention in academic research [2]. For example, several viral vectors have made a clinical impact owing to their exceptional gene transfection efficiency [3]. However, their practical applications are still limited by a few intractable problems, such as immunogenicity, insertional mutagenesis, and the expensive manufacturing processes involved [4]. In contrast, non-viral vectors can elegantly address these limitations, and can be used to facilitate scalable synthesis for different applications [5]. Therefore, increasing effort has been devoted to designing novel non-viral vectors for gene delivery, with the main purpose of improving their gene loading capacity, biocompatibility, and transfection efficiency [6].

Among the various non-viral vectors, cationic polymers hold advantages including high levels of gene loading via electrostatic interaction and the ability to self-assemble into nanoparticles for efficient intracellular delivery [7]. Poly-L-lysine (PLL) and polyethylenimine $(\mathrm{PEI})$ are representative cationic transfection reagents that have been widely used in 
fundamental studies. However, their potential clinical translation has been hindered due to strong cytotoxicity, as a consequence of their high charge density and poor biodegradability [8]. To mitigate this issue, various biodegradable cationic polymers have been reported, such as poly( $\beta$-amino esters) (PAEs), which can be degraded by intracellular esterase, thus, resulting in significantly improved biocompatibility [9]. In addition, PAEs have the beneficial characteristics including structural diversity for flexible synthesis and gene loading capability [10]. For example, compared with linear poly( $\beta$-amino esters) (LPAEs), branched PAEs have been reported to possess a three-dimensional (3D) architecture which provides them with enhanced transfection efficiency [6].

While the branched PAEs showed great promise for gene delivery at the cellular level, there are still several concerns regarding their in vivo application. As poly-cationic nanocomplexes, PAEs-based vehicles could inevitably interact with biological macromolecules, which could induce opsonization by the reticuloendothelial system (RES), resulting in rapid clearance and decreased transfection efficiency [7]. In addition, the electrostatic interaction of the vehicles with erythrocyte membranes causes membrane disruption and hemolysis [11]. One simple solution is to coat nanoparticle surface with a shell layer to form a negatively charged polyanion/polycation/nucleic acid ternary complex [12]. For this purpose, hyaluronic acid (HA), a natural linear polyanionic polymer, has been widely used due to its characteristics including excellent biocompatibility, biodegradability and lack of immunogenicity [13]. By virtue of its anionic nature, HA can be readily coated on the surface of PAEs-based vehicles, and the biosafety of the nano-complex can be markedly enhanced.

It should be noted that surface modification not only affects the biocompatibility of the nano-system, but also changes the transfection efficiency, which is the key parameter for gene delivery vectors. This is understandable, as HA modification usually reverses the surface charge to negative, thus, impeding the accessibility of the nano-vehicles to the negatively charged cell membrane [14]. While free HA is reported to actively target cells overexpressing CD44 receptors [15], such bind force is impeded after its coating on a PAEs surface due to the steric hinderance and strong attraction between HA and the positively charged PAEs core [16]. Therefore, surface engineering is still required to optimize the interaction between the nanoparticles and cell membrane in order to achieve enhanced gene transfection efficiency, while maintaining biosafety.

To overcome this dilemma, we report on dopamine (DA)-grafted HA coated hyperbranched PAEs/DNA nano-complexes for enhanced gene delivery (Scheme 1). DA is a hormone and neurotransmitter in biology, while DA-grafted polymers have been found to exhibit bio-adhesive abilities, increasing cell membrane interactions [17]. Additionally, DA can be used as an active targeting ligand to enhance the internalization of nanoparticles into tumor cells with high expression of DA receptors [18]. DA-grafted HA (HA-DA) with different DA grafting degrees was facile synthesized via a one-step carbodiimide coupling method, and further coated on the surface of PAEs/DNA to form a core-shell nanostructure. After material and nanoparticle characterization, the nano-structure was demonstrated to be highly biocompatible after surface HA-DA modification. Interestingly, the higher DA grafting degree gave rise to better cellular uptake of the HA-DA coated PAEs/DNA by A549 cells (adenocarcinomic human alveolar basal epithelial cells). This can be explained by the bio-adhesive and DA receptor targetability of the grafting DA (A549 cells overexpress the DA receptor on their membrane) [19], which co-contributes to the enhanced cell internalization. As a result, the gene delivery vector with a $43 \%$ DA grafting degree achieved a gene transfection efficiency superior to that of commonly used PEI. This core-shell nano-vector holds great promise for biocompatible and highly efficient gene therapeutic applications. 


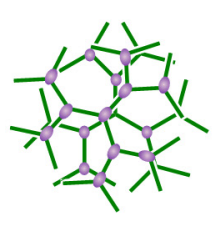

PAEs

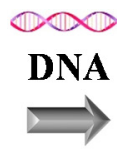

PAEs/DNA

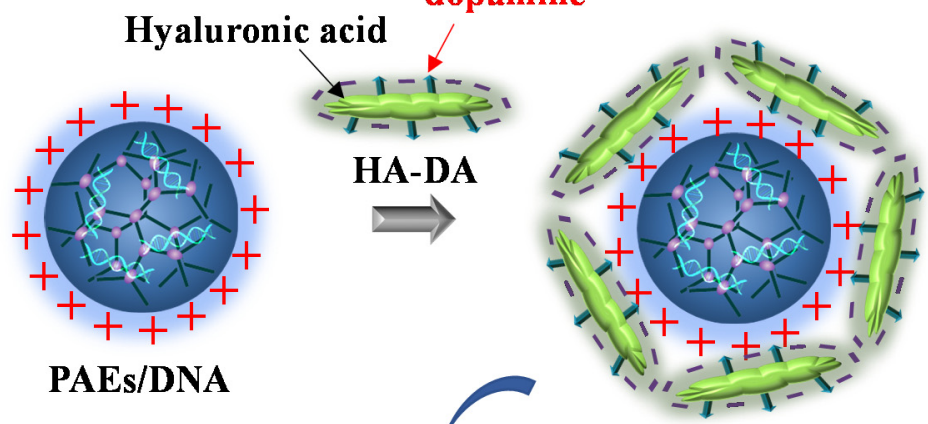

dopamine

HA-DA/PAEs/DNA

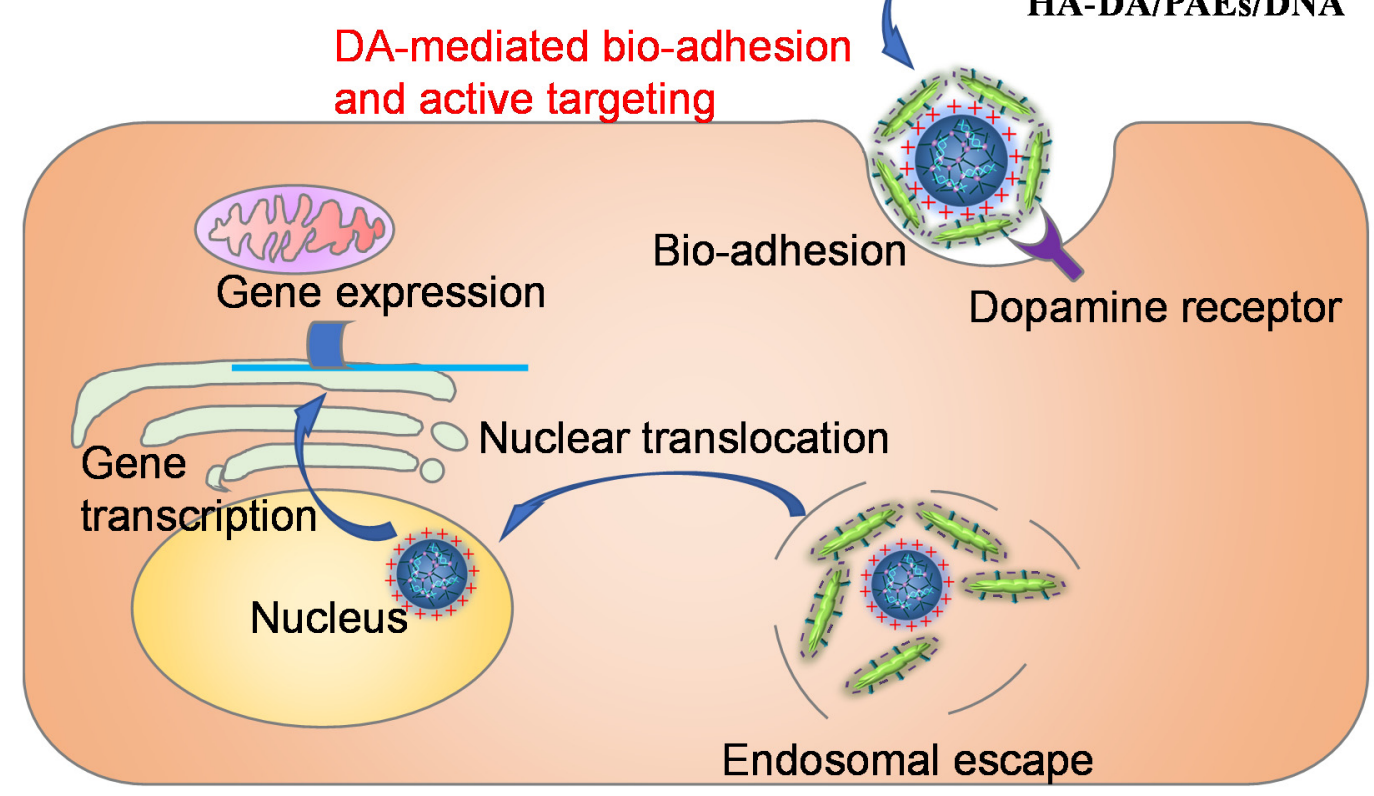

Scheme 1. Schematic illustrating the construction of HA-DA/PAEs/DNA nano-vector for enhanced gene delivery via DA-mediated bio-adhesion and active binding. DA: dopamine; HA: hyaluronic acid; HA-DA: DA-grafted HA; PAE: poly( $\beta$-amino esters).

\section{Materials and Methods}

\subsection{Materials}

Acryloyl chloride, glycerol, 5-amino-1-pentanol and 1,3-diaminopropane were purchased from Shanghai Sun-shine Chemical Technology, Co., Ltd. (Shanghai, China). Hyaluronic acid $\left(\mathrm{HA}, \mathrm{M}_{\mathrm{W}}=7 \mathrm{kDa}\right.$ ) was obtained from Shandong Runxin Biotechnology Co., Ltd. (Shandong, China). Dopamine hydrochloride and 1-(3-Dimethylaminopropyl)-3ethylcarbodiimide hydrochloride were obtained from Energy Chemical (Shanghai, China). The luciferase DNA was obtained from Promega (Madison, WI, USA), and the fluorescent labeled DNA was from Sangon Biotech Co., Ltd. (Shanghai, China) (sequence and modification: FAM-ACGCATCTGTGAAGAGAACCTGGG). Branched polyethyleneimine $\left(\mathrm{PEI}, M_{\mathrm{W}}=25 \mathrm{kDa}\right.$ ) and 3-[4, 5-dimethylthiazol-2-yl]-2, 5-diphenyl tetrazolium bromide (MTT) were purchased from Sigma-Aldrich (St. Louis, MO, USA). All other solvents were analytical grade and obtained from Sinopharm Chemical Reagent Co., Ltd. (Beijing, China) unless otherwise noted.

\subsection{Cells}

The human non-small-cell carcinoma (A549) cells were obtained from the Xiangya Cell Center (Changsha, China). The cells were cultured in complete DMEM medium 
(with 10\% $(v / v)$ FBS and $1 \%$ penicillin-streptomycin solution $(100 \mathrm{U} / \mathrm{mL})$ ) at $37^{\circ} \mathrm{C}$ in a humidified atmosphere with $5 \% \mathrm{CO}_{2}$.

\subsection{Preparation of Glycerol Triacrylate (GA)}

Glycerol (5.0 g, $54.3 \mathrm{mmol})$ and triethylamine $(22.6 \mathrm{~mL}, 162.9 \mathrm{mmol})$ were added to $60 \mathrm{~mL}$ dichloromethane in a $250 \mathrm{~mL}$ round-bottom flask, and the mixture was stirred and cooled to $5{ }^{\circ} \mathrm{C}$. Then, acryloyl chloride $(13.7 \mathrm{~mL}, 168.3 \mathrm{mmol})$ was added dropwise to the mixture, and then the mixture was warmed to room temperature and stirred for $12 \mathrm{~h}$. After the reaction, the triethylamine hydrochloride, excessive triethylamine and acryloyl chloride were removed by filtration and evaporation. Dichloromethane $(50 \mathrm{~mL})$ was used to extract glycerol triacrylate, and the organic layer was washed with $20 \%$ sodium bicarbonate aqueous solution three times, dried with $\mathrm{Na}_{2} \mathrm{SO}_{4}$, filtered, and evaporated to obtain the final product. The product had a typical deep orange color with a weight of $11.3 \mathrm{~g}$, based on which, the yield was calculated to be $82 \%$. After purification, the structure was confirmed by ${ }^{1} \mathrm{H}$ NMR, FTIR, and ESI-MS (Figure S1A-C, see in Supplementary Materials). The characteristic data were as follows: ${ }^{1} \mathrm{H}$ NMR $(400 \mathrm{MHz}, \mathrm{DMSO}-\mathrm{d} 6): \delta 6.36-6.30(\mathrm{~m}, 3 \mathrm{H}$, $\underline{\mathrm{H}}-\mathrm{CH}=\mathrm{CH}), 6.20-6.13\left(\mathrm{~m}, 3 \mathrm{H}, \mathrm{CH}_{2}=\mathrm{CH}-\mathrm{C}\right), 5.99-5.96(\mathrm{~m}, 3 \mathrm{H}, \mathrm{H}-\mathrm{CH}=\mathrm{CH}), 5.40-5.35$ (m, $\left.1 \mathrm{H}, \mathrm{O}-\mathrm{CH}_{2}-\mathrm{C} \underline{\mathrm{H}}-\mathrm{O}\right), 4.44-4.29$ (m, 4H, O-C $\left.\underline{\mathrm{H}}_{2}-\mathrm{CH}-\underline{\mathrm{H}}_{2}-\mathrm{O}\right)$. ATR-FTIR: 1727, 1635, 1451, 1407, $1372,1296,1268,1182,1072,984,907,860,809,663 \mathrm{~cm}^{-1}$; ESI-MS spectrum $\mathrm{m} / z$ : calculated for glycerol triacrylate $=254.1$, and $[\mathrm{M}+\mathrm{H}]^{+}=255.1$.

\subsection{Preparation of PAES}

To synthesize PAEs, 1,4-butanediol diacrylate $(5.0 \mathrm{~g}, 25.2 \mathrm{mmol})$, glycerol triacrylate (256.2 $\mathrm{mg}, 1.0 \mathrm{mmol})$ and 5-amino-1-pentanol (2.2 g, $21.0 \mathrm{mmol})$ were mixed in glass vial and continuously vigorously stirred in the dark at $90^{\circ} \mathrm{C}$ for $24 \mathrm{~h}$. Then, acrylate-terminated poly ( $\beta$-amino esters) was dissolved in DMSO $(160 \mu \mathrm{L}, 500 \mathrm{mg} / \mathrm{mL})$, followed by adding $640 \mu \mathrm{L}$ 1,3-diaminopropane solution ( $0.25 \mathrm{M}$ in DMSO), followed by a $24 \mathrm{~h}$ incubation at room temperature under vigorous shaking. To collect PAEs, the final reaction mixture was added to $8 \mathrm{~mL}$ diethyl ether for $20 \mathrm{~min}$ incubation to allow for complete precipitation. The final PAE product was collected by washing twice with diethyl ether and drying under reduced pressure.

\subsection{Acid-Base Titration}

For each $8 \mathrm{~mL}$ solution (150 mM NaCl, $2 \mathrm{mg} / \mathrm{mL}$ PAEs, $2 \mathrm{mg} / \mathrm{mL}$ PEI), NaOH was added to adjust the $\mathrm{pH}$ to 9 . Then, $\mathrm{HCl}(0.1 \mathrm{M})$ was titrated, and the $\mathrm{pH}$ value of each solution was monitored until the $\mathrm{pH}$ value reached 4 , and the total volume decrease in $\mathrm{HCl}$ was used to calculate the relative buffering capacity, in which the buffering capacity of PEI was set as $100 \%$.

\subsection{Preparation of $H A-D A s$}

HA (500 mg) was dissolved in $50 \mathrm{~mL}$ PBS (pH 5.5). Dopamine hydrochloride (237.1 mg, $1.3 \mathrm{mmol}$ ) and 1-(3-Dimethylaminopropyl)-3-ethylcarbodiimide hydrochloride (EDC $\cdot \mathrm{HCl})$ (240.0 mg, $1.3 \mathrm{mmol}$ ) were added under vigorous stirring. The $\mathrm{pH}$ value of the mixture was adjusted to 5.5, followed by $2 \mathrm{~h}$ incubation under stirring. The HA-DA product was collected by freeze-drying after dialysis (Molecular Weight Cut Off, MWCO = 3500 Da) against acidic water ( $\mathrm{pH}$ 5.5) and deionized water, respectively.

\subsection{Preparation and Characterization of PAEs/DNA and HA-DAs/PAEs/DNA}

To prepare PAEs/DNA, PAEs and DNA were dissolved in sodium acetate buffer (20 mM, pH 5.5). Then, $100 \mu \mathrm{L}$ of an equal amount of DNA $(0.04 \mathrm{mg} / \mathrm{mL})$ was mixed with $100 \mu \mathrm{L}$ of various concentrations of PAEs at PAEs/DNA weight ratios of 1:1, 10:1, 20:1, 40:1 and 80:1. After a $10 \mathrm{~s}$ vortex, the mixture was incubated for $10 \mathrm{~min}$ at room temperature to form PAEs/DNA. To prepare HA-DAs/PAEs/DNA, the PAEs/DNA (40:1) was mixed with HA-DAs at different weight ratios (HA-DAs/DNA) of 0:1, 1:1, 2.5:1, 5:1, 10:1. After 
incubation for $10 \mathrm{~min}$, the nano-vector was formed. The size and zeta potential were evaluated by dynamic light scattering (DLS) (Malvern Zetasizer Nano ZS, Worcestershire, UK), and the morphology was characterized by transmission electron microscopy (TEM, Zeiss Libra 200, Carl Zeiss AG Ltd., Oberkochen, Germany), after staining with 2\% (w/v) sodium phosphotungstate solution.

\subsection{In Vitro Cytotoxicity Assays}

The in vitro cytotoxicity was evaluated by MTT (3-(4,5-dimethyl thiazol-2-yl)-5-diphenyl tetrazolium bromide) assay. A549 cells were seeded in 96-well plates at a density of $5 \times 10^{3}$ cells/well and cultured with complete medium for $24 \mathrm{~h}$. The medium was replaced by serum-free medium $(100 \mu \mathrm{L} /$ well $)$ with different nano-complexes $(0.2 \mu \mathrm{g}$ DNA per well). After $4 \mathrm{~h}$, the medium was replaced by $100 \mu \mathrm{L}$ complete medium, followed by $48 \mathrm{~h}$ incubation at $37^{\circ} \mathrm{C}$. Subsequently, $20 \mu \mathrm{L}$ MTT solution $(5 \mathrm{mg} / \mathrm{mL}$ in PBS) was added for $4 \mathrm{~h}$ incubation. The medium was removed and $100 \mu \mathrm{L}$ DMSO was added to dissolve the formed formazan crystals. The absorbance at $490 \mathrm{~nm}$ was measured by a microplate reader (Infinite M200 pro, Tecan Group Ltd., Männedorf, Switzerland).

\subsection{Hemolysis Test}

The pure erythrocytes were obtained by centrifugation ( $3000 \mathrm{rpm}, 10 \mathrm{~min}$ ) of the whole mouse blood and washing four times. Different nano-complexes $(100 \mu \mathrm{L}$, containing $0.2 \mu \mathrm{g}$ DNA) were mixed with $100 \mu \mathrm{L} 4 \%$ erythrocytes $(v / v)$ for $4 \mathrm{~h}$ incubation at $37^{\circ} \mathrm{C}$. Triton $\mathrm{X}-100$ and saline were used as positive and negative controls, respectively. After centrifugation, the absorbance (A) of the supernatant was measured at $540 \mathrm{~nm}$ for hemolysis activity calculation. Hemolysis activity $(\%)=\left[\left(\mathrm{A}_{\text {Polyplexes }}-\mathrm{A}_{\text {Negative }}\right) /\left(\mathrm{A}_{\text {Positive }}-\mathrm{A}_{\text {Negative }}\right)\right] \times 100$.

\subsection{Cell Uptake}

A549 cells were seeded in 24 -well plates at a density of $1 \times 10^{5}$ cells / well and cultured for $24 \mathrm{~h}$. Then, the medium was replaced by DMEM medium containing different nanocomplexes ( $1 \mu \mathrm{g}$ DNA per well). After $4 \mathrm{~h}$ incubation at $37^{\circ} \mathrm{C}$, the cells were washed three times with cold PBS, and observed by a fluorescence microscope. To quantify the cell uptake level, the mean fluorescence intensity was quantified using flow cytometry.

\subsection{Intracellular Gene Expression}

A549 cells were seeded in 24-well plates at a density of $5 \times 10^{4}$ cells / well and cultured with complete medium for $24 \mathrm{~h}$. Then the medium was replaced by serum-free medium (500 $\mu \mathrm{L}$ /well) with gluciferase DNA-loaded nano-complexes ( $1 \mu \mathrm{g}$ DNA per well). After $4 \mathrm{~h}$ incubation, the transfection medium was replaced with $500 \mu \mathrm{L}$ complete medium, followed by $48 \mathrm{~h}$ incubation at $37^{\circ} \mathrm{C}$. Subsequently, cells were washed with cold PBS and lysed by $1 \times$ Lysis reporter buffer (Beyotime, Shanghai, China). The luciferase activity was measured with microplate reader (Infinite M200 pro, Tecan Group Ltd., Männedorf, Switzerland). Gene transfection efficiency was expressed as the relative bioluminescence intensity per $10^{4}$ cells.

\subsection{Safety Evaluation in Vivo}

Healthy Sprague-Dawley rats were intravenously injected with $500 \mu \mathrm{L}$ HA-DA4/PAEs / DNA (dosage of $10 \mathrm{mg} / \mathrm{kg}$ DNA), and the serum was collected $24 \mathrm{~h}$ after treatment. The blood biochemical parameters, including aspartate aminotransferase (AST), alanine aminotransferase (ALT), blood urea nitrogen (BUN) and creatinine (Cre), were measured using the standard kits, according to the manufacturer's instructions. All animal experiments were performed in accordance with the Regulations for the Administration of Affairs Concerning Experimental Animals of China and approved by the Ethics Committee for Research on Animal Subjects at Xiangya School of Pharmaceutical Sciences of Central South University. This information has been added in the revised manuscript. 


\subsection{Statistical Analysis}

All quantitative data are expressed as the mean \pm standard deviation (SD). Statistically significant differences among groups were assessed using ANOVA analysis. Significance was measured at the following thresholds: ${ }^{*} p<0.05,{ }^{* *} p<0.01,{ }^{* * *} p<0.001$.

\section{Results and Discussions}

\subsection{Preparation and Characterizations of PAEs/DNA}

The branched PAEs were synthesized through a Michael addition reaction of amines and acrylates using glycerol triacrylate as the cross-linker (Figure 1A). As the first step, the cross-linker of glycerol triacrylate was synthesized through the esterification reaction by using glycerol and acryloyl chloride (Figure S1D, see in Supplementary Materials). Then, purified glycerol triacrylate was used as the crosslinker for PAEs generation, in which 5-amino-1-pentanol acted as nucleophile to attack acrylates of 1,4-butanediol diacrylate and glycerol triacrylate. The reaction was carried out under anhydrous conditions to avoid hydrolysis of the sensitive ester bond, thus, achieving effective polymerization and generating high molecular weight polymers [20]. The polymerization was stopped, and then, an excess amount of 1,3-diaminopropane was used to fully end-modify the acrylate-terminated PAEs. The final branched PAEs were characterized by ${ }^{1} \mathrm{H}-\mathrm{NMR}$ (Figure 1B). The chemical shift $(\delta)$ of the main characteristic peaks can be assigned. For example, the peaks at $\delta 1.2-1.5$ and $\delta$ 1.6 can be ascribed to the protons of $-\mathrm{NCH}_{2}\left(\mathrm{CH}_{2}\right)_{3} \mathrm{CH}_{2} \mathrm{OH}$ and $-\mathrm{N}\left(\mathrm{CH}_{2}\right)_{2} \mathrm{COOCH}_{2} \mathrm{CH}_{2}$, respectively. The $\delta 2.2-2.4$ can be attributed to the backbone of $-\mathrm{OCOCH}_{2} \mathrm{CH}_{2} \mathrm{~N}$ - and $\left.-\mathrm{NCH}_{2}\left(\mathrm{CH}_{2}\right)_{4} \mathrm{OH}\right)$, and $\delta$ 2.6-2.7 were from the protons of the $-\mathrm{OCOCH}_{2} \mathrm{CH}_{2} \mathrm{~N}$ - fragment. The $\delta 4.0$ can be ascribed to the fragment of $-\mathrm{N}\left(\mathrm{CH}_{2}\right)_{2} \mathrm{COOCH}_{2} \mathrm{CH}_{2-}$, and the peaks at $84.4-4.6$ can be assigned to the glycerol fragment. All these results confirmed the successful synthesis of PAEs.

We then characterized the properties of PAEs as a carrier for gene delivery. It is known that positively charged polymers can spontaneously attract DNA via electrostatic interaction to form nano-complexes [21]. To explore this, plasmid DNA was mixed with PAEs at different weight ratios, and the formation of nanoparticles was monitored by using a Malvern particle analyzer (Figure 1C). It is well-known that positive polymers load DNA through electrostatic interactions in order to form nanoparticles. At a low weight ratio of $1: 1$, the interaction is poor, and nanoparticles $(\sim 500 \mathrm{~nm})$ were formed with negative charge due to insufficient PAEs being present to fully trap DNA. With increasing the PAEs concentration, the binding force became stronger and was able to effectively condense the DNA, with the particle size gradually decreasing, owing the condensation effect of PAEs. At a ratio of 20:1, the surface charge was reversed to positive. At the optimal ratio of 40:1, the DNA was fully encapsulated, and the particle size reduced to $\sim 100 \mathrm{~nm}$. The morphology of the nanoparticles was further characterized by TEM, which showed quasi-spherical shapes with a uniform size of $\sim 100 \mathrm{~nm}$, consistent with DLS observation (Figure 1D).

One important advantage of amino-based polymers for gene delivery is their capability to facilitate endo/lysosome escape after internalization into targeted cells, which benefits from the "proton sponge effect" [22,23]. This effect was achieved by the proton buffering capacity in an acidic buffer. As a control, the $\mathrm{pH}$ of the $\mathrm{NaCl}$ solution dropped sharply upon addition of $\mathrm{HCl}(0.1 \mathrm{M})$, while both PAEs and PEI showed much slower $\mathrm{pH}$ decreases (Figure 1E), demonstrating the proton buffering ability. We then quantified the results, and the PAEs exhibited a 74\% efficacy, as compared to commercially available PEI (Figure 1F), demonstrating its potential as a carrier for gene delivery. However, PAEs were preferable over PEI, owing to their significantly improved biocompatibility (vide infra).

\subsection{Surface Functionalization of HA-DA}

To achieve HA-DA functionalized PAEs/DNA, we first synthesized the HA-DAs by a one-step carbodiimide coupling method (Figure 2A). The carboxyl groups in the HA backbone were activated by EDC, and then coupled to DA to form HA-DA. After dialysis 
to remove unreacted chemicals and byproducts, the products were obtained by freezedrying for ${ }^{1} \mathrm{H}-\mathrm{NMR}$ characterization. Compared to HA (Figure S2, see in Supplementary Materials), new peaks at chemical shift $(\delta \sim 7)$ emerged, which can be assigned to the protons in orto and the meta coupling position on the ring of DA, demonstrating HA-DA conjugation (Figure 2B). The DA conjugation ratio can be further calculated by the integral area ratio of two regional peaks associated with the ring protons of DA and the protons in the methylene of HA ( $81.9-2.0)$ [24]. As presented in Figure 2C, the HA-DA with different DA grafting ratios can be easily synthesized by tuning the feeding amount of DA and EDC.

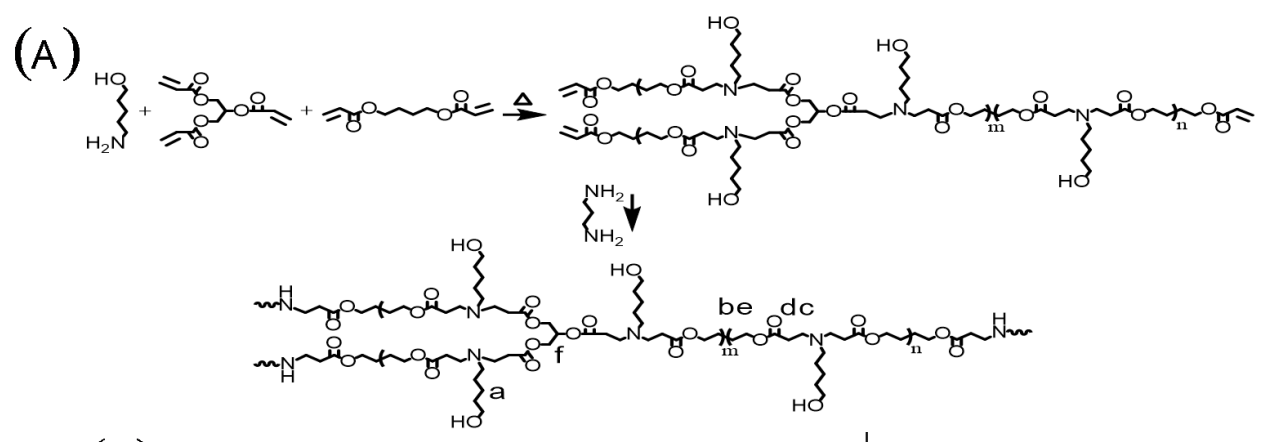

(B)
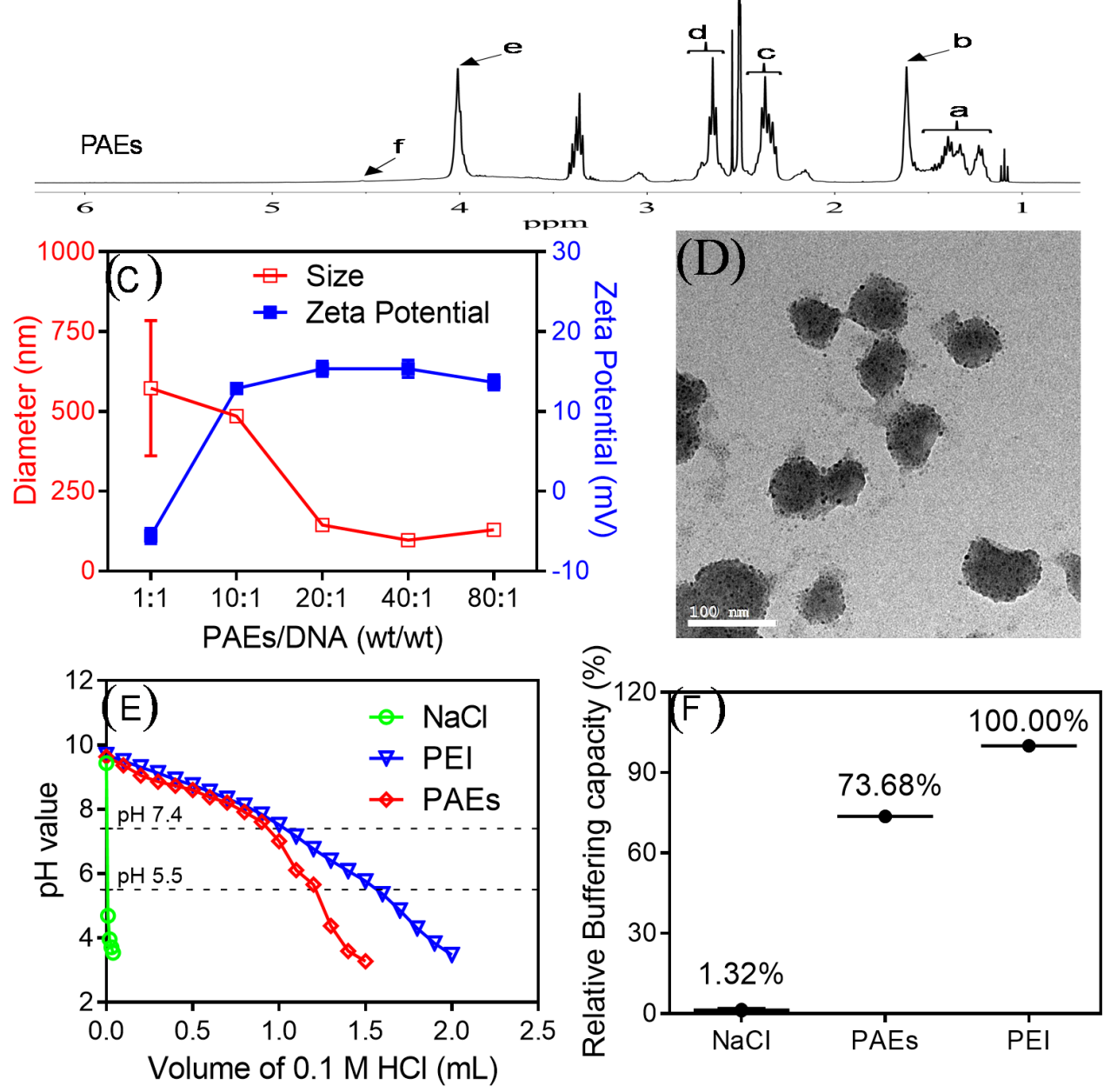

Figure 1. (A) Synthetic protocol of PAEs. (B) ${ }^{1} \mathrm{H}$ NMR spectrum of PAEs (DMSO-d6). The chemical shift of the important protons can be assigned in A. (C) Particle size and zeta potential of PAEs/DNA at different weight ratios (wt/wt). The DNA concentration was fixed at $0.02 \mathrm{mg} / \mathrm{ml}$, and the polymer concentrations were varied to give different ratios. (D) TEM image of PAEs/DNA at weight ratio of 40:1. (E) Acid-base titration curve for different solutions. (F) Quantification of relative buffering capacity. 
(A)

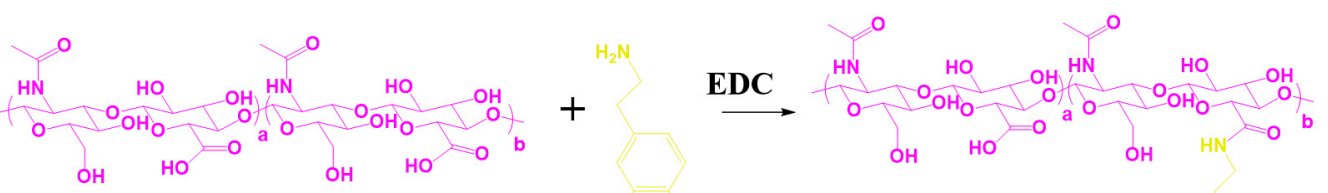

(B)

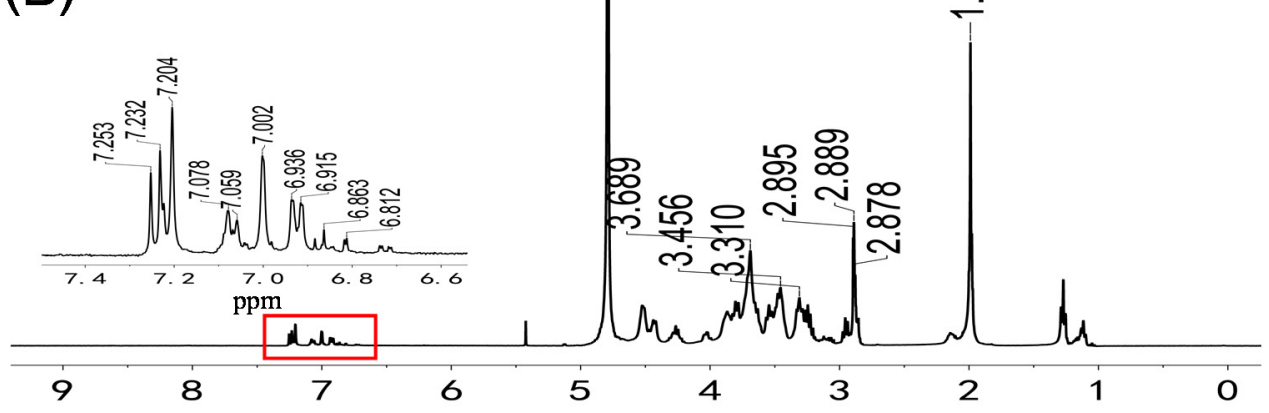

ppm

\begin{tabular}{ccccc} 
(C) Coating & HA (mg) & DA (mmol) & EDC (mmol) & Grafting degree $^{\text {a }}(\%)$ \\
\hline HA-DA1 & 500 & 0.4 & 0.4 & 17 \\
HA-DA2 & 500 & 0.8 & 0.8 & 25 \\
HA-DA3 & 500 & 1.3 & 1.3 & 36 \\
HA-DA4 & 500 & 1.7 & 1.7 & 43 \\
\hline
\end{tabular}

${ }^{\mathrm{a}}$ The grafting degrees of DA were estimated by ${ }^{1} \mathrm{H}$ NMR.

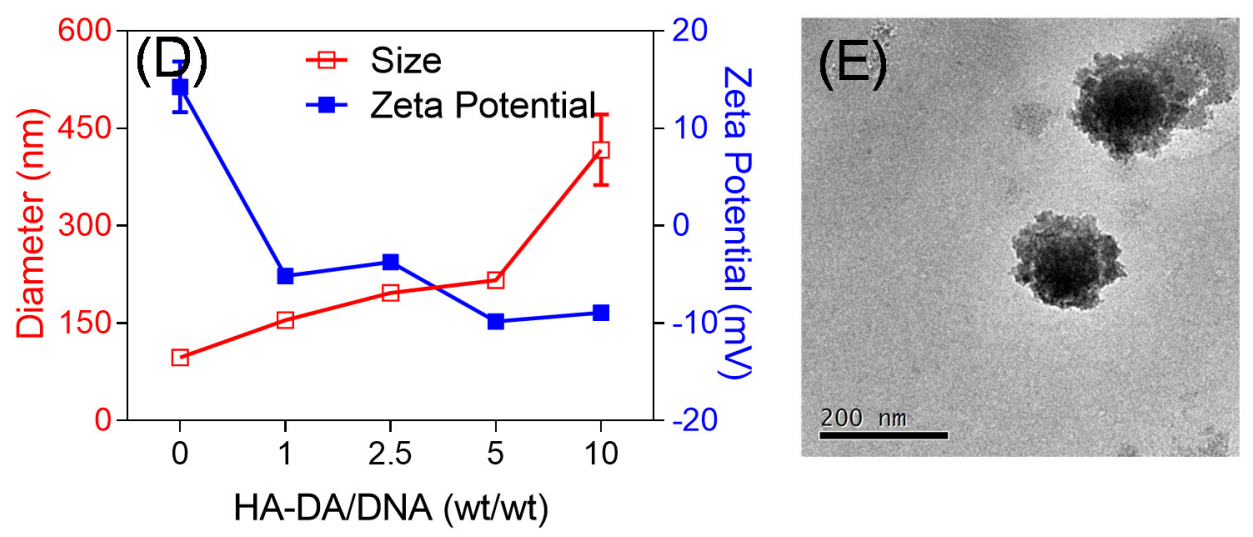

Figure 2. (A) Synthetic protocol of HA-DA. (B) ${ }^{1} \mathrm{H}-\mathrm{NMR}$ spectrum of HA-DA $\left(\mathrm{D}_{2} \mathrm{O}\right)$. (C) The synthesis of HA-DA with different DA grafting degrees by tuning the feeding amount of DA and EDC.HCl. (D) Particle size and zeta potential of HA-DA/PAEs/DNA at different weight ratios of HA-DA/PAEs/DNA (wt/wt/wt). (E) TEM of HA-DA4/PAEs/DNA at weight ratio of 5:40:1.

The HA-DA modified PAEs/DNA (40:1) (termed HA-DA/PAEs/DNA) was simply prepared by mixing PAEs/DNA with HA-DA. The surface HA-DA modification was confirmed by the increase in particle size, as well as the decrease in surface charge (Figure 2D). The HA-DA/PAEs/DNA ratio of 5:40:1 was chosen to ensure sufficient surface modification, while further increases in the HA-DA/PAEs/DNA ratio resulted in particle aggregation. At this ratio, the surface charge became negative, which is beneficial for avoid- 
ing non-specific opsonization by the reticuloendothelial system (RES), thus, resulting in a prolonged circulation half-life [25]. From the TEM image, the HA-DA/PAEs/DNA showed an obvious core-shell structure with a particle size of $\sim 200 \mathrm{~nm}$ (Figure 2E). Note that the HA-DAs with different DA grafting degrees could effectively wrap PAEs/DNA to form nanoparticles with similar sizes (Figure S3, see in Supplementary Materials). Therefore, these nanoparticles with comparable sizes and surface properties can be used to study the effect of the DA grafting degree on cell transfection efficiency.

\subsection{Biocompatibility of the HA-DA/PAEs/DNA}

Cationic polymers have been extensively used for gene delivery, owing to their high DNA loading and effective transfection, while a critical concern regards their biocompatibility for biological applications. For example, the positively charged materials might damage cell membranes via electrostatic interaction, resulting in cell apoptosis [26,27]. To address this, various methods have been developed to modify the polymers to improve their biocompatibility [28,29]. In our case, we employed surface HA-DA modification to alleviate the cytotoxicity, and evaluated the biosafety via MTT assay. Without HA modification, the PAEs displayed a concentration-dependent toxicity (Figure 3A). Nevertheless, PAEs performed favorably over PEI, showing a much lower cytostatic activity. This can be attributed to the ester bond linkage of the polymer, which is prone to degradation by esterase in the cytoplasm [30]. In this respect, PAEs hold promise as transfection reagents. Moreover, upon HA-DA modification, the biocompatibility was significantly improved, with almost $100 \%$ cell viability after $48 \mathrm{~h}$ incubation (Figure $3 \mathrm{~B}$ ). We also tested HA-DA with different DA grafting degrees, and similar results were observed. Therefore, HA-DA modification could effectively detoxify PAEs/DNA for biomedical applications. Such detoxification can be ascribed to the charge reversion effect of HA-DA on the PAEs/DNA surface. Compared with unmodified HA [31], HA-DA was much more effective at screening the surface charge of PAEs/DNA, likely due to the bio-adhesive property of DA to facilitate HA-DA adsorption.

Another limitation of cationic polymer-based nanocarriers for in vivo gene delivery is their nonspecific interaction with blood components. The interaction between nanocarriers and erythrocyte membranes easily causes membrane disruption, giving rise to hemolysis. Next, we performed a hemolytic activity assay to evaluate the biocompatibility of the nanoparticles. Normal saline and Triton X-100 were used as negative the control and positive control, respectively. For PAEs/DNA with a weight ratio up to 40:1, the nano-complex showed low hemolytic activity, while further increases in the weight ratio of PAEs/DNA caused obvious hemolysis (Figure 3C). Overall, the PAEs/DNA was sufficiently biocompatible for intravenous injection. In addition, such biocompatibility was maintained after HA-DA modification with different weight ratios, showing less than $5 \%$ hemolysis (the criterion defined by ASTM F756-17 for medical biomaterials) (Figure 3D) [16]. To test the biocompatibility in vivo, the mice were intravenously injected with the nano-vector, and the blood biochemical indexes of alanine aminotransferase (ALT), aspartate aminotransferase (AST) (indicators of liver), creatinine (Cre) and blood urea nitrogen (BUN) (indicators of kidney) were analyzed. All these parameters were within the normal range (Figure S4, see in Supplementary Materials), further demonstrating the excellent biosafety of the nano-system in vivo.

\subsection{Intracellular Transfection and Gene Expression}

Having confirmed the biocompatibility, we studied the intracellular performance of the nanocomplex by using A549 cancer cells as an example. To explore cellular uptake, the DNA was covalently labeled with a FAM (6-carboxy-fluorescein) fluorophore to visualize intracellular delivery of the DNA-loaded nano-complex. After $4 \mathrm{~h}$ incubation, the PAEs/DNA showed green fluorescence inside cells (Figure 4A), indicating the successful internalization of the nanoparticles. This is reasonable, as the positively charged nanoparticles can readily penetrate inside cells. Interestingly, HA-DA modified nanoparticles with 
higher DA grafting degrees exhibited brighter fluorescence inside cells. While the overall internalization efficiency of PEI/DNA was much higher, its strong cytotoxicity limits its applications. To facilitate a quantitative comparison, we performed a flow cytometry analysis (Figure S5, see in Supplementary Materials), and the quantified intensity is shown in Figure 4B. Consistent with fluorescent images, the HA-DA/PAEs/DNA displayed a general trend of cellular uptake, in which a higher DA grafting degree gave rise to an improved uptake efficiency. With HA-DA4 modification (the DA grafting degree reached $43 \%$ ) (Figure 2C), the HA-DA4/PAEs/DNA achieved a three-fold higher intensity than PAEs/DNA, demonstrating its potential for gene transfection.
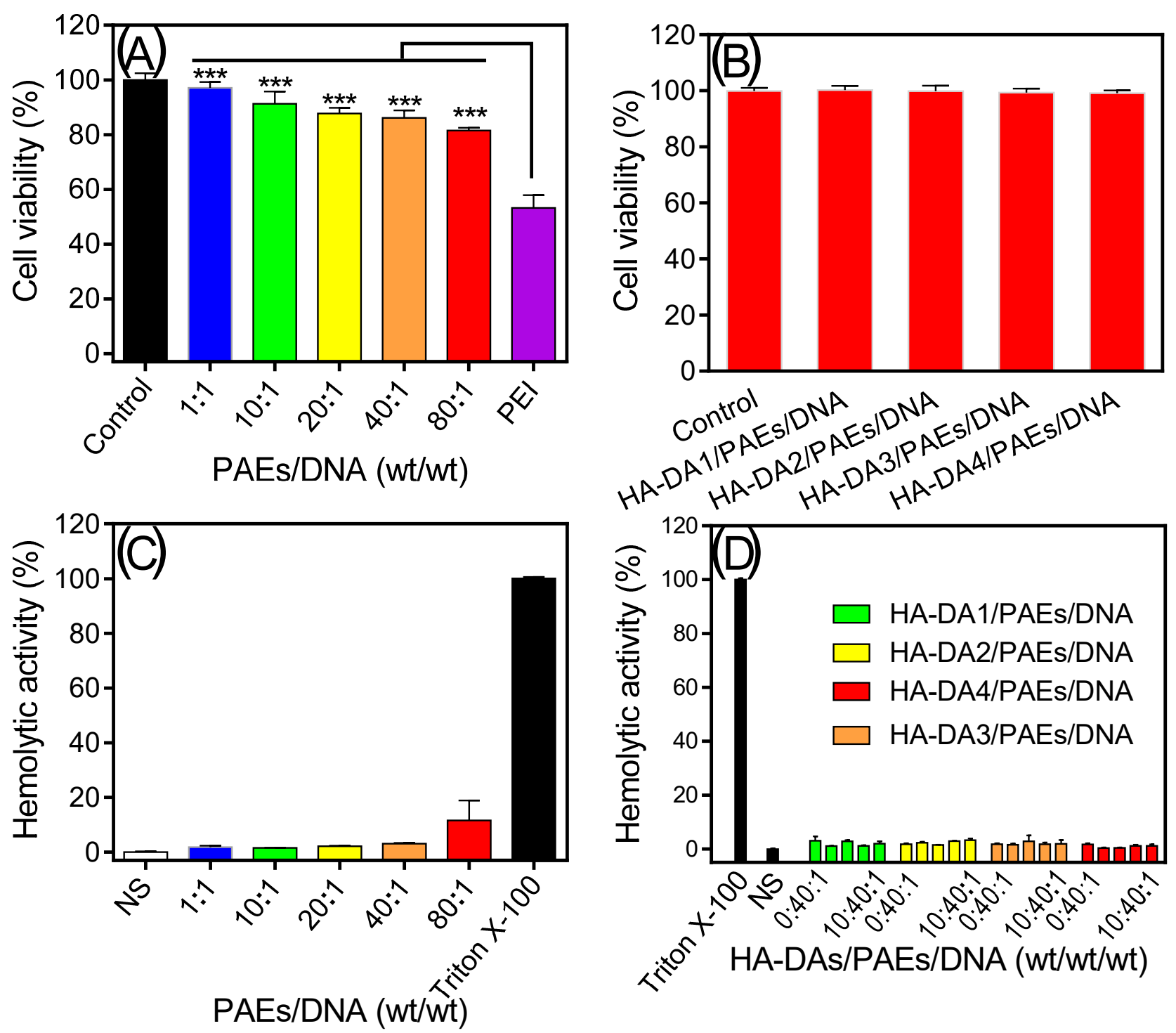

Figure 3. (A, B) Cytotoxicity and (C, D) hemolysis evaluation of PAEs/DNA and HA-DAs/PAEs/DNA at different weight ratios. As for hemolysis assay, Triton X-100 and normal saline (NS) were used as positive and negative controls, respectively. The PEI/DNA weight ratio was 3:1. ${ }^{* * *} p<0.001$. For panel A and B, the DNA concentration was $2 \mu \mathrm{g} / \mathrm{mL}$ and the weight ratio of HA-DA/PAEs/DNA was 5:40:1.

Finally, the gene transfection efficiency was further confirmed by exploring gene expression inside cells. As a proof-of-concept, a plasmid DNA with a luciferase reporter gene was loaded into the nanosystems, which enabled convenient evaluation of gene expression by measuring the bioluminescence. Compared with PAEs/DNA, the HA-DA4/PAEs showed a seven-fold higher level of gene expression (Figure 4C), consistent with the above 
fluorescent imaging result. Note that the gene expression of HA-DA4/PAEs was also higher than that of PEI/DNA, further confirming the superiority of HA-DA4/PAEs for gene delivery. Therefore, DA modification could effectively facilitate the intracellular delivery of the nanosystem, and this can be explained by several mechanisms. First, the DA receptor is reported to be overexpressed on various types of tumor cells, including A549 cells [32]. Therefore, the DA modifications can be regarded as types of active ligands, which mediate the transportation of nanoparticles via the DA receptor. In addition, the DA modification endows the nanosystem with a bio-adhesive property, thus, promoting the attachment of nanoparticles on the cell membrane [33]. Collectively, the HA-DA4/PAEs/DNA is an excellent choice for gene delivery and can be used for in vivo applications in the future.
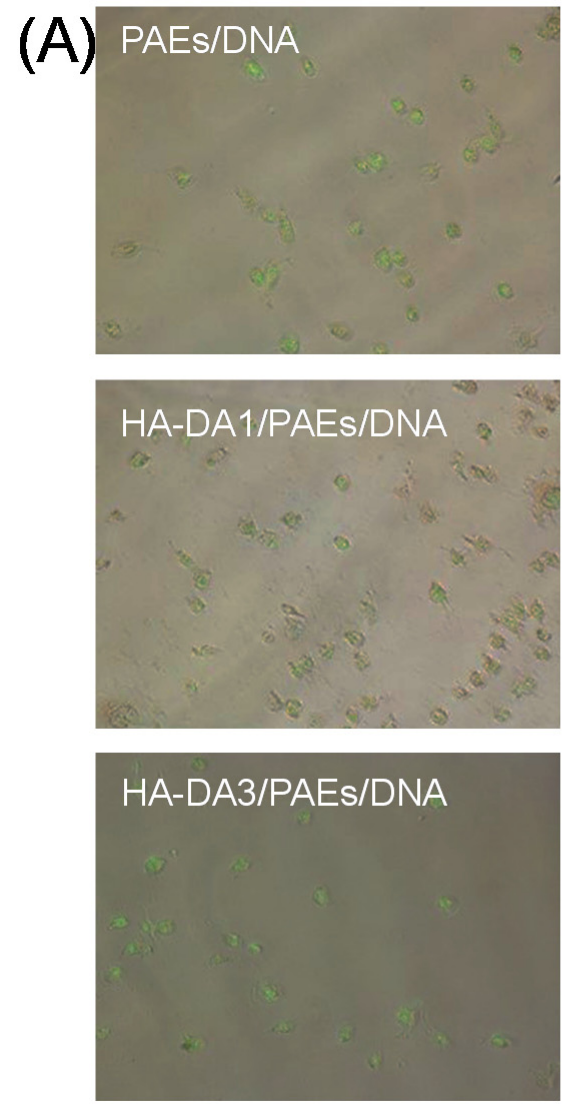
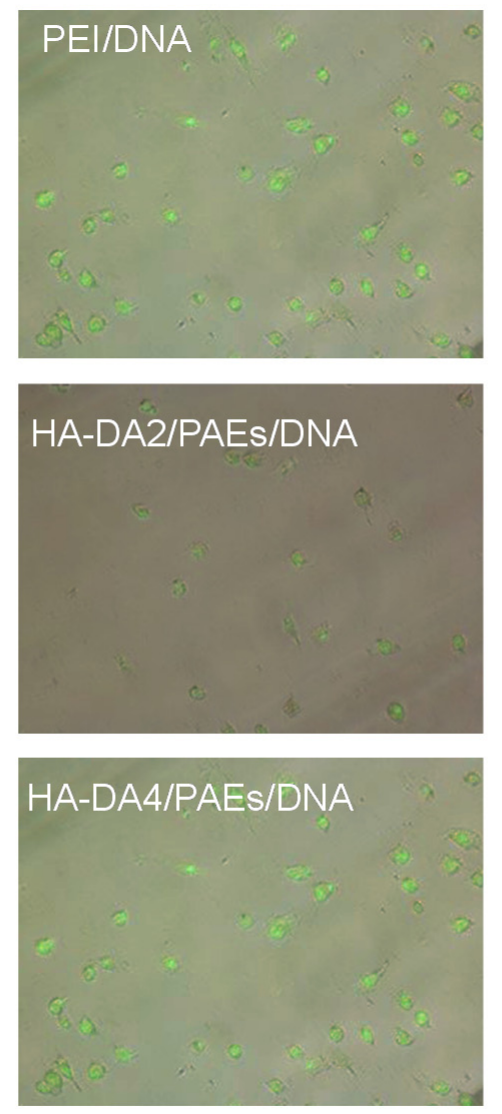
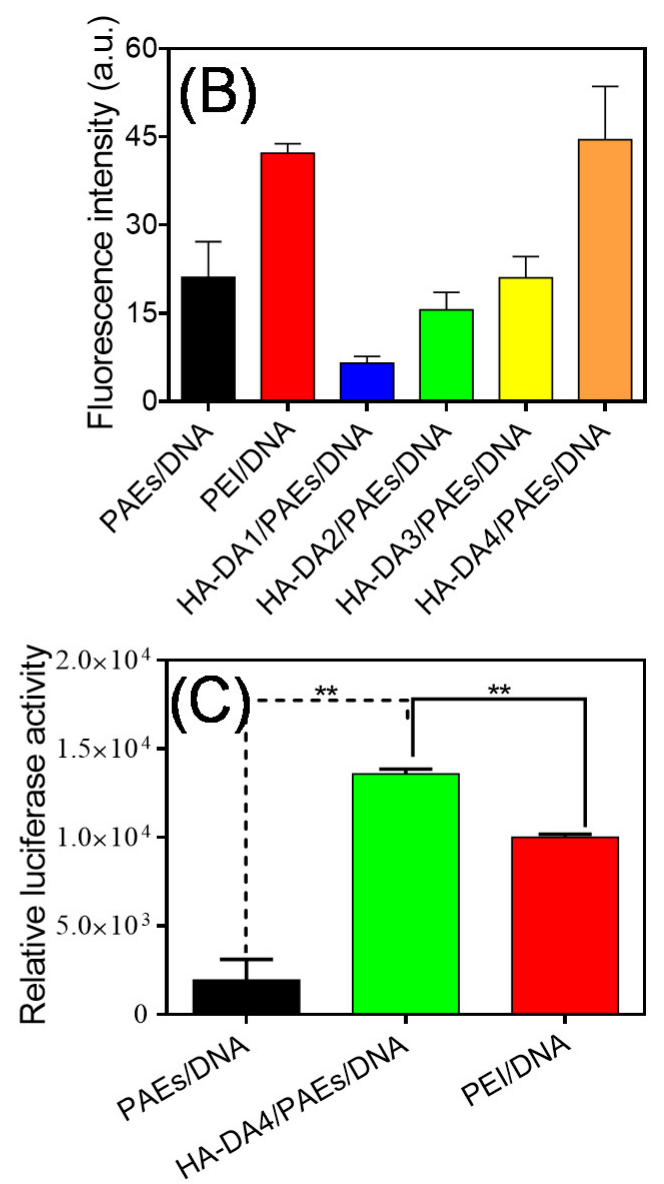

Figure 4. (A) Merged pictures of fluorescent images and bright-field images of cells after incubating with PAEs/DNA (40:1), PEI/DNA (40:1) or HA-DA/PAEs/DNA (10:40:1) for $4 \mathrm{~h}$. The DNA concentration was fixed at $0.5 \mu \mathrm{M}$. (B) Quantified flow cytometry intensity for different treating groups. (C) Gene expression level for PAEs/DNA, HA-DA4/PAEs/DNA and PEI/DNA in A549 cells. ${ }^{* *} p<0.01$.

\section{Conclusions}

In summary, we synthesized a new type of PAE using glycerol as a cross-linker, which can effectively compress DNA to form a PAEs/DNA nano-complex. The nanocomplex displayed satisfactory proton buffering capability, and the surface positive charge enabled the HA-DA coating to form a core-shell nanostructure. HA-DA modification reduced the cytotoxicity of PAEs/DNA, and more importantly, allowed for the tuning of the transfection efficiency by adjusting the DA grafting degrees. DA modification endowed the nano-vector with an adhesive property and targetability towards the DA receptor, which co-contributes to the enhanced gene transfection. By using the HA-DA4 coating (with DA grafting degree of $43 \%$ ), the resulting nano-vector achieved a level of gene expression that was even better than that of the PEI-based vector. Therefore, it can be 
envisaged that HA-DA4/PAEs/DNA may be a useful vector for assisting gene delivery in vivo. For example, owing to its targetability towards A549 cancer cells, such nano-vector could be used for lung cancer therapy by delivering gene therapeutics, such as plasmids, siRNAs, and CRISPER/cas9 systems [34].

Supplementary Materials: The following are available online at https://www.mdpi.com/article/10 .3390 / cryst11040347/s1, Figure S1: The structure characterization of glycerol triacrylate, Figure S2: The ${ }^{1} \mathrm{H}$ NMR of HA, Figure S3: The size and zeta potential of HA-DAs/PAEs/DNA with different DA grafting degrees, Figure S4: Serum biochemical parameters after treatment with the nano-vector, Figure S5: Flow cytometry analysis the uptake of different vehicles.

Author Contributions: Conceptualization, W.Z., X.Q. and Y.M.; investigation, M.G.; data curation, M.G., Y.M.; writing—original draft preparation, W.Z., X.Q.; writing-review and editing, W.Z.; supervision, W.Z. and X.Q.; funding acquisition, W.Z. and X.Q. All authors have read and agreed to the published version of the manuscript.

Funding: This research was funded by National Natural Science Foundation of China (No. 21804144, U1903125), Foundation of Hunan Educational Committee (20B071). The APC was funded by Foundation of Hunan Educational Committee (20B071).

Institutional Review Board Statement: The study was conducted according to the guidelines of the Declaration of Helsinki and approved by "Ethics Committee of Laboratory Animal Welfare of Central South University" (protocol code No. 20200415).

Informed Consent Statement: Not applicable.

Data Availability Statement: Not applicable.

Conflicts of Interest: The authors declare no competing financial interest.

\section{References}

1. Geary, R.S.; Norris, D.; Yu, R.; Bennett, C.F. Pharmacokinetics, biodistribution and cell uptake of antisense oligonucleotides. Adv. Drug Deliv. Rev. 2015, 87, 46-51. [CrossRef]

2. Roberts, T.C.; Langer, R.; Wood, M.J.A. Advances in oligonucleotide drug delivery. Nat. Rev. Drug Discov. 2020, 19, 673-694. [CrossRef]

3. Wang, F.; Qin, Z.; Lu, H.; He, S.; Luo, J.; Jin, C.; Song, X. Advances in oligonucleotide drug delivery. J. Gene Med. 2019, 21 , e3108.

4. Yin, H.; Kauffman, K.J.; Anderson, D.G. Delivery technologies for genome editing. Nat. Rev. Drug Discov. 2017, 16, 387-399. [CrossRef]

5. Mashel, T.V.; Tarakanchikova, Y.V.; Muslimov, A.R.; Zyuzin, M.V.; Timin, A.S.; Lepik, K.V.; Fehse, B. Overcoming the delivery problem for therapeutic genome editing: Current status and perspective of non-viral methods. Biomaterials 2020, 258, 120282. [CrossRef]

6. Zhou, D.; Gao, Y.; Ahern, J.O.; O’Keeffe Ahern, S.A.; Xu, Q.; Huang, X.; Greiser, U.; Wang, W. Improved cell adhesion and osteogenesis of op-HA/PLGA composite by poly (dopamine)-assisted immobilization of collagen mimetic peptide and osteogenic growth peptide. ACS Appl. Mater. Interfaces 2016, 8, 34218-34226. [CrossRef] [PubMed]

7. Pack, D.W.; Hoffman, A.S.; Pun, S.; Stayton, P.S. Design and development of polymers for gene delivery. Nat. Rev. Drug Discov. 2005, 4, 581-593. [CrossRef] [PubMed]

8. Van Bruggen, C.; Hexum, J.K.; Tan, Z.; Dalal, R.J.; Reineke, T.M. Nonviral gene delivery with cationic glycopolymers. Acc. Chem. Res. 2019, 52, 1347-1358. [CrossRef] [PubMed]

9. Kozielski, K.L.; Tzeng, S.Y.; de Mendoza, B.A.H.; Green, J.J. Bioreducible cationic polymer-based nanoparticles for efficient and environmentally triggered cytoplasmic siRNA delivery to primary human brain cancer cells. ACS Nano 2014, 8, 3232-3241. [CrossRef]

10. Zugates, G.T.; Anderson, D.G.; Little, S.R.; Lawhorn, I.E.B.; Langer, R. Synthesis of poly ( $\beta$-amino ester) s with thiol-reactive side chains for DNA delivery. J. Am. Chem. Soc. 2006, 128, 12726-12734. [CrossRef]

11. Akagi, T.; Kim, H.; Akashi, M. pH-dependent disruption of erythrocyte membrane by amphiphilic poly (amino acid) nanoparticles. J. Biomater. Sci. Polym. Ed. 2010, 21, 315-328. [CrossRef] [PubMed]

12. Zhang, W.; Cheng, Q.; Guo, S.; Lin, D.; Huang, P.; Liu, J.; Wei, T.; Deng, L.; Liang, Z.; Liang, X.-J.; et al. Gene transfection efficacy and biocompatibility of polycation/DNA complexes coated with enzyme degradable PEGylated hyaluronic acid. Biomaterials 2013, 34, 6495-6503. [CrossRef] [PubMed]

13. Yu, Y.; Zhu, S.; Hou, Y.; Li, J.; Guan, S. Sulfur Contents in Sulfonated Hyaluronic Acid Direct the Cardiovascular Cells Fate. Acs Appl. Mater. Interfaces 2020, 12, 46827-46836. [CrossRef] [PubMed] 
14. Zaki, N.M.; Nasti, A.; Tirelli, N. Nanocarriers for cytoplasmic delivery: Cellular uptake and intracellular fate of chitosan and hyaluronic acid-coated chitosan nanoparticles in a phagocytic cell model. Macromol. Biosci. 2011, 11, 1747-1760. [CrossRef] [PubMed]

15. Choi, K.Y.; Han, H.S.; Lee, E.S.; Shin, J.M.; Almquist, B.D.; Lee, D.S.; Park, J.H. Hyaluronic acid-Based activatable nanomaterials for stimuli-responsive imaging and therapeutics: Beyond CD44-mediated drug delivery. Adv. Mater. 2019, 31, 1803549. [CrossRef] [PubMed]

16. Gu, J.; Chen, X.; Ren, X.; Zhang, X.; Fang, X.; Sha, X. CD44-targeted hyaluronic acid-coated redox-responsive hyperbranched poly (amido amine)/plasmid DNA ternary nanoassemblies for efficient gene delivery. Bioconjug. Chem. 2016, 27, 1723-1736. [CrossRef]

17. Zhou, D.; Li, S.; Pei, M.; Yang, H.; Gu, S.; Tao, Y.; Ye, D.; Zhou, Y.; Xu, W.; Xiao, P. Dopamine-modified hyaluronic acid hydrogel adhesives with fast-forming and high tissue adhesion. ACS Appl. Mater. Interfaces 2020, 12, 18225-18234. [CrossRef]

18. Masoudipour, E.; Kashanian, S.; Maleki, N. A targeted drug delivery system based on dopamine functionalized nano graphene oxide. Chem. Phys. Lett. 2017, 668, 56-63. [CrossRef]

19. Roy, S.; Lu, K.; Nayak, M.K.; Bhuniya, A.; Ghosh, T.; Kundu, S.; Ghosh, S.; Baral, R.; Dasgupta, P.S.; Basu, S.J. Activation of D2 dopamine receptors in CD133+ ve cancer stem cells in non-small cell lung carcinoma inhibits proliferation, clonogenic ability, and invasiveness of these cells. Biol. Chem. 2017, 292, 435-445. [CrossRef]

20. Sunshine, J.; Green, J.J.; Mahon, K.P.; Yang, F.; Eltoukhy, A.A.; Nguyen, D.N.; Langer, R.; Anderson, D.G. Small-molecule end-groups of linear polymer determine cell-type gene-delivery efficacy. Adv. Mater. 2009, 21, 4947-4951. [CrossRef]

21. Zhou, D.; Cutlar, L.; Gao, Y.; Wang, W.; O’Keeffe-Ahern, J.; McMahon, S.; Duarte, B.; Larcher, F.; Rodriguez, B.J.; Greiser, U.; et al. The transition from linear to highly branched poly ( $\beta$-amino ester) s: Branching matters for gene delivery. Sci. Adv. 2016, 2, e1600102. [CrossRef]

22. Sato, T.; Ishii, T.; Okahata, Y. In vitro gene delivery mediated by chitosan. Effect of $\mathrm{pH}$, serum, and molecular mass of chitosan on the transfection efficiency. Biomaterials 2001, 22, 2075-2080. [CrossRef]

23. Boussif, O.; Lezoualc'h, F.; Zanta, M.A.; Mergny, M.D.; Scherman, D.; Demeneix, B.; Behr, J.P. Guanidinium-cholesterol cationic lipids: Efficient vectors for the transfection of eukaryotic cells. Proc. Natl. Acad. Sci. USA 1995, 92, 7297-7301. [CrossRef] [PubMed]

24. Zhang, X.; Li, Z.; Yuan, X.; Cui, Z.; Yang, X. Fabrication of dopamine-modified hyaluronic acid/chitosan multilayers on titanium alloy by layer-by-layer self-assembly for promoting osteoblast growth. Appl. Surf. Sci. 2013, 284, 732-737. [CrossRef]

25. Gustafson, H.H.; Holt-Casper, D.; Grainger, D.W.; Ghandehari, H. Nanoparticle uptake: The phagocyte problem. Nano Today 2015, 10, 487-510. [CrossRef]

26. Kargaard, A.; Sluijter, J.P.G.; Klumperman, B. Polymeric siRNA gene delivery-transfection efficiency versus cytotoxicity. J. Control. Release 2019, 316, 263-291. [CrossRef]

27. Vaidyanathan, S.; Anderson, K.B.; Merzel, R.L.; Jacobovitz, B.; Kaushik, M.P.; Kelly, C.N.; van Dongen, M.A.; Dougherty, C.A.; Orr, B.G.; Holl, M.M.B. Quantitative Measurement of Cationic Polymer Vector and Polymer-pDNA Polyplex Intercalation into the Cell Plasma Membrane. ACS Nano 2015, 9, 6097-6109. [CrossRef] [PubMed]

28. Wen, S.; Zheng, F.; Shen, M.; Shi, X. Surface modification and PEGylation of branched polyethyleneimine for improved biocompatibility. J. Appl. Polym. Sci. 2013, 128, 3807-3813. [CrossRef]

29. Song, J.; Li, X.; Li, Y.; Che, J.; Li, X.; Zhao, X.; Chen, Y.; Zheng, X.; Yuan, W. Biodegradable and biocompatible cationic polymer delivering microRNA-221/222 promotes nerve regeneration after sciatic nerve crush. Int. J. Nanomed. 2017, 12, 4195-4208. [CrossRef] [PubMed]

30. Dong, H.; Pang, L.; Cong, H.; Shen, Y.; Yu, B. Application and design of esterase-responsive nanoparticles for cancer therapy. Drug Deliv. 2019, 26, 416-432. [CrossRef]

31. An, T.; Zhang, C.; Han, X.; Wan, G.; Wang, D.; Yang, Z.; Wang, Y.; Zhang, L.; Wang, Y. Hyaluronic acid-coated poly ( $\beta$-amino) ester nanoparticles as carrier of doxorubicin for overcoming drug resistance in breast cancer cells. RSC Adv. 2016, 6, 38624-38636. [CrossRef]

32. Clarke, S.J.; Hollmann, C.A.; Aldaye, F.A.; Nadeau, J.L. Effect of ligand density on the spectral, physical, and biological characteristics of CdSe/ZnS quantum dots. Bioconjug. Chem. 2008, 19, 562-568. [CrossRef] [PubMed]

33. Hong, S.; Yang, K.; Kang, B.; Lee, C.; Song, I.T.; Byun, E.; Park, K.I.; Cho, S.-W.; Lee, H. Recapitulation of in vivo-like paracrine signals of human mesenchymal stem cells for functional neuronal differentiation of human neural stem cells in a 3D microfluidic system. Adv. Funct. Mater. 2013, 23, 1774-1780. [CrossRef]

34. Perez, J.C.A.; Martin-Padron, J.; Arenas, A.; Rodriguez, M.; Medina, P. EP1.14-25 Development of New Lung Cancer Therapies Based on Gene-Editing Technologies. J. Thorac. Oncol. 2019, 14, S1041. [CrossRef] 